\title{
2,3-butanediol in experimental myocardial ischaemia in pigs
}

\author{
K. R. Heer, U. Althaus, D. Mettler, W. Schilt and H. Thoelen \\ Departement Forschung Kantonsspital Basel, Klinik für Thorax-, Herz- und Gefässchirurgie Inselspital Bern, \\ Switzerland
}

KEY WORDS: Myocardial ischaemia, intermediary metabolism, 2,3-butanediol, pigs.

To investigate the role of 2,3-butanediol in myocardial ischaemia we analysed this compound in pig's myocardium and blood. Ischaemia was induced by ligation of a coronary artery. In the first study we found significantly higher levels of 2,3butanediol in the homogenate of ischaemic myocardium than in non-ischaemic myocardium. The lactate concentration was also significantly elevated. In the second study, where ischaemia was similarly induced, and where reperfusion was achieved

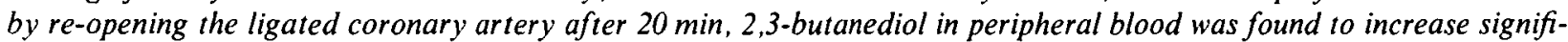
cantly. In the pigs in which the coronary artery was not re-opened, the 2,3-butanediol level in peripheral blood was unchanged. We conclude that in pigs' anaerobic myocardia accumulation of 2,3-butanediol occurs; if the myocardium is reperfused this metabolite also appears in the blood.

\section{Introduction}

2,3-butanediol is a product from the intermediary metabolism; its precursors are pyruvate, acetaldehyde and acetoin $^{[1.2]}$. Similar to lactate, the formation of this product is accelerated under anaerobic conditions ${ }^{[3]}$. Abnormal lactate extraction does occur in ischaemic myocardium and abnormal levels of lactate are found in coronary sinus but not in peripheral blood ${ }^{[4]}$. To investigate the possible role of 2,3-butanediol as a peripheral biochemical marker for anaerobic metabolism, we analysed it in ischaemic and non-ischaemic myocardium of five pigs (tissue study). In a second study (plasma study) we compared plasma levels in two groups of pigs: in the first five pigs the occluded coronary artery was reopened after $20 \mathrm{~min}$, whereas in the second five the occlusion was maintained during the study.

\section{Methods}

\section{ANIMAL PREPARATIONS}

Pigs were chosen because their coronary distributions, unlike other species, are not subjected to wide variations. The animals, weighing from 20 to $25 \mathrm{~kg}$, were premedicated intramuscularly with ketamine hydrochloride $\left(10 \mathrm{mg} \mathrm{kg}^{-1}\right)$ and intravenously with atropine sulfate $\left(1 \mathrm{mg} \mathrm{kg}^{-1}\right)$. Anaesthesia was induced with intravenous azaperone $\left(2 \mathrm{mg} \mathrm{kg}^{-1}\right)$ and metomidate $\left(5 \mathrm{mg} \mathrm{kg}^{-1}\right)$. Following tracheal intubation, respiration was controlled using a volume ventilator supplying oxygen-enriched room air; anaesthesia was maintained by adding fluothane to the gas mixture $(0.5-1 \cdot 5 \%)$. Venous blood sampling was performed from a superior caval catheter and arterial blood pressure was measured by a Statham transducer by cannulating the carotid artery.

Through a left thoracotomy the left anterior descending coronary artery (LAD) was dissected distally to the

\footnotetext{
Submitted for publication on 1 November 1988. and in revised form 24 November 1989.

Correspondence: Dr Kaspar Heer, Spezialarzt für Innere Medizin, Spez. Herzkrankheiten. Kasernenstr. 22a. 4410 Liestal. Switzerland.
}

origin of the first diagonal branch and a suture passed around the dissected blood vessel, in order to obtain a permanent or temporary occlusion. Ventricular arrhythmias were treated with intravenous lignocaine $(20 \mathrm{mg})$ and electrical defibrillation was carried out if ventricular fibrillation occurred.

\section{Experimental protocol}

STUDY A (TISSUE STUDY)

Coronary occlusion was maintained for $10 \mathrm{~min}$ in five pigs. The animals were then sacrificed and the heart immediately removed. Two specimens of $1 \mathrm{~g}$ were excised, both from ischaemic and non-ischaemic areas of myocardium and prepared for analysis of 2,3-butanediol and lactate.

\section{STUDY B (PLASMA STUDY)}

Two pigs from the same litter were used for each experiment. The animals were randomized and divided into two groups. In five pigs the dissected coronary artery remained ligated permanently (group A) and in another five coronary perfusion was restored following a $20 \mathrm{~min}$ occlusion (group B). In the latter group the end of the thread passed around the LAD was drawn through a small and rigid rubber tube to cause temporary occlusion without kinking ${ }^{(5)}$. In both groups the chest was closed in layers and the animals were allowed to recover.

For serial determinations of 2,3-butanediol, samples of venous blood were periodically drawn from the caval catheter prior to, and during, the $2 \mathrm{~h}$ following permanent or temporary occlusion. Twenty-four $h$ after the surgical procedure the animals were anaesthetized with intravenous sodium pentobarbital $\left(30 \mathrm{mg} \mathrm{kg}^{-1}\right)$ and put to death. The heart was rapidly excised and deep frozen to facilitate slicing.

\section{ANALYSIS OF 2,3-BUTANEDIOL AND LACTATE}

2,3-butanediol

Study $A$. One g of excised muscle was treated with $4 \mathrm{ml}$ of phosphate buffer and homogenized. $10 \mathrm{ml}$ of $10 \%$ 
trichloroacetic acid and $20 \mathrm{ml}$ of water were added. The mixture was shaken and centrifuged. The supernatant solution was decanted and deep frozen.

Study $B$. Samples of $10 \mathrm{ml}$ venous blood were treated with $10 \mathrm{ml}$ of $10 \%$ sodium tungstate and $10 \mathrm{ml}$ of sulphuric acid. $20 \mathrm{ml}$ of water was added: the mixture was then centrifuged and the supernatant solution decanted and deep frozen.

2,3-butanediol was determined using the methods described by Westerfeld ${ }^{[6]}$ and Happold and Spencer ${ }^{[7]}$. Values are given in $\mu \mathrm{molg}^{-1}$ (study A) and $\mu \mathrm{moll}^{-1}$ (study B). In our laboratory the relative coefficient of variation is less than $5 \%$. Lactate was analysed using the method described by Passonneau ${ }^{[8]}$.

\section{ASSESSMENT OF INFARCT SIZE}

The frozen ventricles were cut into parallel slices and incubated in a solution of nitro-benztoluene as described in our previous report $\mathrm{t}^{[\mathrm{s}]}$. Tetrazolium in nitro-benztoluene is reduced by the dehydrogenase systems of the intact mitochondria to insoluble diformazane, staining normal myocardium dark-blue and leaving infarcted areas almost white. This technique permitted a clear identification of necrotic myocardial tissue and allowed quantitative assessment of the infarcted area using a morphometric point counting method.

\section{STATISTICS}

Paired and unpaired t-tests were used for statistical analysis.

\section{Results}

\section{STUDY A (TISSUE STUDY)}

Distributions of 2,3-butanediol were: 18.74 \pm $1.75 \mu \mathrm{mol} \mathrm{g}^{-1}$ in ischaemic and $14.29 \pm 0.75 \mu \mathrm{mol} \mathrm{g}^{-1}$ in non-ischaemic myocardium $(P<0.001)$, and lactate: $27.93 \pm 2.31 \mathrm{mmol} \mathrm{g}^{-1}$ in ischaemic and $16.67 \pm$ $4.62 \mathrm{mmol} \mathrm{g}^{-1}$ in non-ischaemic myocardium $(P<0.01)$ (Fig. 1).

\section{STUDY B (PLASMA STUDY)}

In those pigs in which the occlusion was maintained for only $20 \mathrm{~min}$ (group B), 2,3-butanediol increased gradually and significantly from $7.83 \pm 1.87 \mu \mathrm{mol} \mathrm{I}^{-1}$ to $11.44 \pm 2.31 \mu \mathrm{mol} \mathrm{l}^{-1}$ in samples taken $40 \mathrm{~min}$ after reopening $(P<0.02)$. This elevated level was also significantly higher than the $60 \mathrm{~min}$ level in pigs where the artery remained occluded (group A, $P<0.02$ ). The decline after the peak level was gradual; 100 min after re-opening, 2,3butanediol was in the range of the initial values. In pigs in which the occlusion was maintained during the entire study (group A), 2,3-butanediol remained unchanged: $8.03 \pm 1.68 \mu \mathrm{moll}^{-1}$ and $7.85 \pm 1.45 \mu \mathrm{moll}^{-1}$ before and $60 \mathrm{~min}$ after occlusion respectively (Fig. 2).

\section{INFARCT SIZE}

In pigs in which the occlusion was re-opened after $20 \mathrm{~min}$, no infarct could be documented histochemically and morphometrically; in pig hearts with maintained

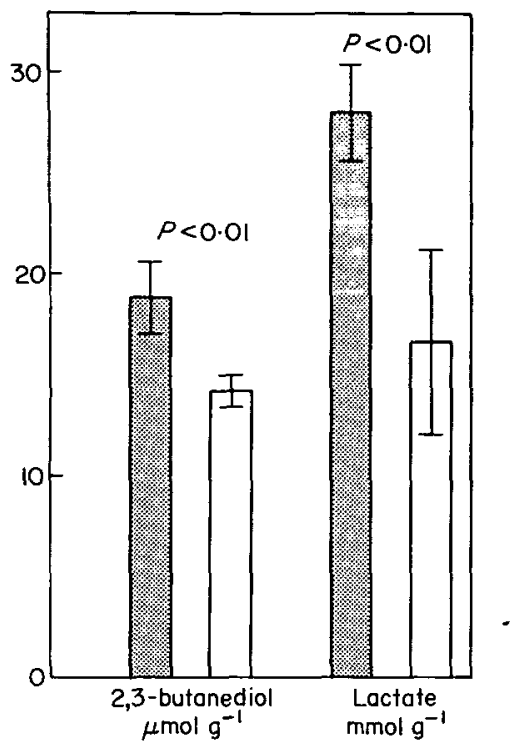

Figure 1 2,3-butanediol and lactate in homogenate of pig hearts' ischaemic (囚) and non-ischaemic ( $\square$ ) myocardium.
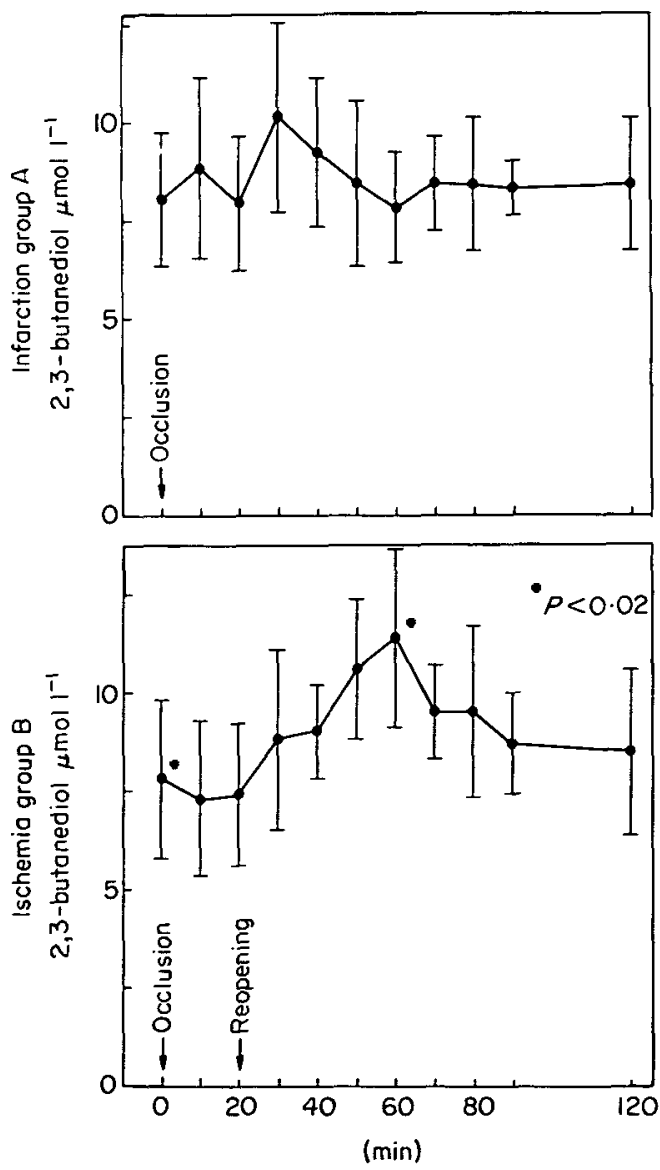

Figure 2 Time-related pattern of 2,3-butanediol in pigs' blood with and without permanent occlusion of the coronary artery (group A versus group B). 
Table 1 Infarct size (\%) in group $A$ and group $B$

\begin{tabular}{cccc}
\hline $\begin{array}{c}\text { Group A, Occlusion of left } \\
\text { coronary artery }\end{array}$ & $\begin{array}{c}\text { Group B, Occlusion of left } \\
\text { coronary artery; reopening } \\
\text { after 20 min }\end{array}$ \\
\hline Pig 1 & $14.4 \%$ & Pig I & $0 \%$ \\
Pig 2 & $16.7 \%$ & Pig 2 & $0 \%$ \\
Pig 3 & $18.9 \%$ & Pig 3 & $0 \%$ \\
Pig 4 & $18.6 \%$ & Pig 4 & $0 \%$ \\
Pig 5 & - & Pig 5 & $0 \%$ \\
\hline
\end{tabular}

occlusion, the infarct size varied between 14.4 and $18.9 \%$. Figures are given for four pigs only; the fifth died in the experiment (Table 1).

\section{Discussion}

Little is known about the metabolic pathway of 2,3butanediol. From in vitro studies it has been proposed that its precursor is mainly a condensation product from two molecules of pyruvate; it is then reduced by a butanedioldehydrogenase to form 2,3-butanedio ${ }^{[1,2]}$. Under anaerobic conditions it can be expected that this diolformation is increased similar to the production of lactate. In our homogenate study (study A) we were able to confirm this hypothesis: in ischaemic myocardium we found significantly more 2,3-butanediol and lactate than in nonischaemic myocardium in the same pig heart (Fig. 1). Although we could not undertake studies with a shorter ischaemic time, we assume that this diol formation takes place very rapidly. The products are then accumulated in the ischaemic cell; the further metabolism within the cell is unknown. In the second study (study B) we demonstrated that by re-opening the occluded vessel, these products could be washed out into the blood. Forty min after reopening a coronary artery which had been occluded for $20 \mathrm{~min}$ we found a gradual and significant increase of 2,3butanediol $(P<0.02$, Fig. 2). The concentration may depend on the extension of the ischaemic area; the proto- col, however, did not allow us to measure the ischaemic area during occlusion; from the infarct study we assume that this area was nearly the same in all five pigs (between 14.4 and $18.9 \%$ ). The decline after the peak value was also gradual and $100 \mathrm{~min}$ laterinitial values were achieved. This finding is in accordance with Söling et al. who concluded from their in vivo infusion study that 2,3-butanediol disappears from the blood within hours ${ }^{(9)}$.

We conclude that in pigs, anaerobic conditions in the myocardium can lead to the accumulation of 2,3butanediol in myocardial tissue; if the myocardium is reperfused 2,3-butanediol also appears in the blood. The results suggest that 2,3-butanediol is a marker for ischaemic metabolism in heart muscle.

We gratefully acknowledge the technical assistance of Mr Ferenc Toth and the staff of the experimental unit of the Inselspital Bern.

\section{References}

[1] Schreiber G, Kohlhaw G, Goede HW, Holzer H. Die Biosynthese von Acetoin in Schweineherzmuskel. Biochem Zeitschrift 1963; 339: 83-93.

[2] Veech RL, Gitomer WL, Casazza JP. Metabolic pathwaysleading to diol formation. Genet Alcohol 1987; 185-99.

[3] Järnefelt J. Studies on the enzymatic synthesis and breakdown of acetoin in the animal organism. Ann Acad Sci Fenn 1955; V: $1-78$.

[4] Opie LH, Owen P, Thomas M, Samson R. Coronary sinus lactate measurements in assessment of myocardial ischaemia. Am J Cardiol 1973; 32: 295-305.

[5] Althaus U, Gurtner HP, Baur H, Hamburger S, Roos B. Consequences of myocardial reperfusion following temporary coronary occlusion in pigs; effects on morphologic, biochemical and hemodynamic findings. Eur J Clin Invest 1977; 7: 437.

[6] Westerfeld WW. Colorimetric determination of blood acetoin. J Biol Chem 1945; 161: 495-502.

[7] Happold FC, Spencer CP. The bacterial formation of acethylmethylcarbinol and 2,3-butylene glycol. Biochim Biophys Acta (AMST) 1952; 8: 18-29.

[8] Passonneau JV. Bestimmung von Lactat. In: Bergmeyer HU, ed. Methoden der enzymatischen Analyse. Chemie. Weinheim, 1974; 1515-7.

[9] Söling HD, Kohlhaw G, Schnermann J, Holzer H, Creutzfeldt W. Zur Bedeutung des Acetoins für die Pathogenese des Coma hepaticum 1964; 89: 457-63. 